This item was submitted to Loughborough's Research Repository by the author.

Items in Figshare are protected by copyright, with all rights reserved, unless otherwise indicated.

\title{
Modelling of creep and fracture properties of nickel based alloys
}

PLEASE CITE THE PUBLISHED VERSION

https://doi.org/10.1080/02670836.2016.1164959

\section{PUBLISHER}

Taylor \& Francis $@$ Institute of Materials, Minerals and Mining

\section{VERSION}

AM (Accepted Manuscript)

\section{PUBLISHER STATEMENT}

This work is made available according to the conditions of the Creative Commons Attribution-NonCommercialNoDerivatives 4.0 International (CC BY-NC-ND 4.0) licence. Full details of this licence are available at: https://creativecommons.org/licenses/by-nc-nd/4.0/

\section{LICENCE}

CC BY-NC-ND 4.0

\section{REPOSITORY RECORD}

Faulkner, Roy G., S. Vujic, Fabio Di Martino, and Simon C. Hogg. 2017. "Modelling of Creep and Fracture Properties of Nickel Based Alloys". figshare. https://hdl.handle.net/2134/26492. 


\title{
Modelling of Creep and Fracture Properties of Nickel Based Alloys
}

\author{
R.G. Faulkner*, S.Vujic**, F. Di Martino*, and S. Hogg* \\ * Department of Materials, Loughborough University, Loughborough, LE11 3TU, UK \\ **Materials, University of Graz, Austria
}

\begin{abstract}
This paper reviews the differences between two nickel based alloys, Alloy 740 and Alloy $740 \mathrm{H}$. Microstructural evolution models are used to forecast the changes in volume fraction and interparticle spacing of both grain boundary (GB) and intragranular precipitates in the alloys. These data are then employed in continuum damage mechanics models to forecast creep curves, and in fracture mechanics models to forecast Charpy impact energies. The results reveal the key microstructural features that control secondary and tertiary creep rate as well as the time dependence of Charpy impact energy after high temperature exposure.
\end{abstract}

\section{Introduction}

Considerable developments in nickel based alloys and stainless steels have taken place in recent years. The driving force has been from the power industry, where requirements for strengths in excess of $100 \mathrm{MPa}$ for times of greater than 50 years at temperatures in the $750{ }^{\circ} \mathrm{C}$ regime are demanded [1-9]. The time scales of any set of creep experiments necessary to demonstrate the effectiveness of this approach in meeting the demand are necessarily very long. Hence the importance of modelling in speeding up the process of improving materials for high temperature use.

This paper describes models that can be used to predict creep and fracture properties in austenitic steels and nickel based alloys. All models rely on predicting microstructural evolution at high temperature, and require a thermodynamic database to predict the phases expected. Evolution is considered using a variety of diffusion-based analytical methods to indicate the kinetics of the material's approach to equilibrium forecast by the thermodynamic models. The evolution of the size, shape and spatial distribution of second phase particles has been treated by simulation models using Monte Carlo methods to describe the spatial distribution of particles within a box as a function of time and temperature [10]. The nucleation of the particles follow classical nucleation kinetics (Johnson-Russell) and depending on the relative energies of the particle-matrix interfaces and the grain boundaries these particles will form either inter-or intra-granularly. Thus a simulation of a 3D piece of the material can be produced at any time instant at a given temperature. 
These microstructural evolution data can be used to forecast creep curves using continuum damage mechanics models based on microstructural parameters [10-11]. The main controlling damage parameter is the inter-particle spacing for the phase controlling the strength of the materials [8-11]. In the case of many nickel based alloys this phase is gamma prime.

The microstructural evolution data can also be used to forecast room temperature fracture toughness variations [10]. This information also can be fed into the CDM models through the GB cavity damage parameter, so that creep curve prediction can be further improved, particularly in the tertiary regime.

The approach is used to predict creep and fracture properties in an advanced nickel based alloy, Alloy 740, in a similar manner to an earlier publication on this alloy [12]. Validation exercises are undertaken to confirm the effectiveness of the model. Fracture is an important issue for austenitic steels and nickel based alloys because all these materials suffer a dramatic loss of room temperature Charpy impact fracture energy after long periods at high temperature. Also creep strength of Alloy 740 is considerably higher than many other alloys in the same composition range, so it is important to explore the reasons for this using short-term modelling exercises. After this exercise, the model is then extended to forecast how fracture and creep properties might be achieved through a modified version of Alloy 740 , Alloy $740 \mathrm{H}$.

\section{Microstructural Evolution Models}

These models are based on simulation techniques and have been developed independently at Loughborough [12] and in Graz [9]. An array of nuclei are defined at random positions within a box surrounded by a grain boundary, and are assessed after small incremental time intervals, $\Delta$ t. The nucleation rate equations of RussellJohnson are used to determine the number density that are allowable for the temperature concerned and for the particular transformation being considered. In each time interval $\Delta \mathrm{n}$ nuclei are formed

$$
\Delta n=Z \beta^{*} \frac{N}{x_{\theta}} \exp \left(-\frac{\Delta G^{*}}{k T}\right) \Delta t
$$

Where $Z$ is the Zeldovitch factor, $\beta^{*}$ is a supply term involving the activation energy for nucleus formation, $\mathrm{N}$ is the number of atomic sites available, $\mathrm{x}_{\theta}$ is the molar fraction of solute atoms in the nucleus phase, $\mathrm{k}$ is Boltzmann's constant and $\mathrm{T}$ is the absolute temperature. For heterogeneous nucleation

$$
\Delta G^{*}=\frac{16 \pi \gamma^{3}}{\Delta G v^{2}}
$$

Where $y$ is the difference between the particle-matrix interfacial energy and the grain boundary energy being destroyed during heterogeneous nucleation, and $\Delta G_{v}$ is the volume free energy driving force for the transformation, dependent on temperature and matrix solute supersaturation. 
The energy consideration allows differentiation between heterogeneous or homogeneous nucleation. Thus precipitation may occur in the simulation grain or on the grain boundary. As more precipitates form the solute supersaturation diminishes and the activation energy barrier increases until nucleation stops, and $\Delta \mathrm{n}$ becomes zero.

Once nucleation is complete, the growth stage takes over and each particle grows at rates governed by the diffusion equations with boundary conditions ranging from the solute alloy composition to the equilibrium solute composition at the particle matrix interface. Diffusion data used depend upon whether grain boundary or inter-granular precipitation is being considered.

Once all of the solute is used up, particle coarsening takes over. This is described within the model by assessing the solute concentration distribution between adjacent particles. Larger particles will have a lower equilibrium interface solute concentration than smaller particles, because of the Gibbs-Thompson effect. This is a much more effective method to deal with coarsening than that used with the Lifshitz-Wagner analytical coarsening equation [13].

The net result is that, at any instant in time, the total precipitate spatial and size distribution is known, and precipitate size distributions can be located to grain boundary and intra-granular populations. A consequence is that the volume fraction of each phase present, and its character (grain boundary or intra-granular), can be tracked over the whole time interval being considered. Additionally, because a record of the spatial distribution of precipitates is maintained throughout the precipitation sequence, the inter-particle spacing can be monitored as a function of time.

In this paper these latter two features (inter-particle spacing and phase volume fraction) are predicted for a variety of temperatures for Alloys 740 and $740 \mathrm{H}$. They are then employed to forecast the fracture and creep properties of the alloys using methods described in the next sections.

\section{Continuum Damage Mechanics Modelling of Creep Properties}

Based on knowledge of the microstructural evolution an equation has been developed by Dyson [11] to forecast the creep rate at any time instant. If all the creep rates at each time interval over the material creep life are integrated, a creep curve is generated. This approach has been shown to be highly successful for high alloy ferritic steels [8]. The incremental creep rate is given by

$$
\varepsilon=\frac{\dot{\varepsilon}_{0}}{\left(1-D_{d}\right)\left(1-D_{s}\right)} \sinh \left[\frac{\sigma(1-H)}{\sigma_{0}\left(1-D_{p}\right)\left(1-D_{n}\right)}\right]
$$

Where $\dot{\varepsilon}_{0}$ is a base line creep rate constant, fixed for nickel based alloys as $7400 \mathrm{~s}^{-1}, \sigma$ is the applied stress, $(1-\mathrm{H})$ is a hardening parameter, dependent on the 
hardness of the alloy. In the case of Alloy 740 and $740 \mathrm{H},(1-\mathrm{H})$ is taken as $5 \times 10^{-18}$. The damage parameters, prefixed with $\mathrm{D}$ represent the following.

$D_{d}$ : a dislocation density -related term responsible for describing primary creep, fixed at 0.99 for all calculations used in this paper.

$D_{s}$ : a solute hardening term which is presumed to be fixed for austenitic materials, and therefore the materials discussed in this paper, as 0.05 .

$D_{\mathrm{p}}$ : the dominant inter-particle spacing term in secondary creep, which is time and temperature-dependent, and can be taken from the output from the microstructural evolution models.

$D_{n}$ : a GB cavity or GB embrittling phase density parameter important in tertiary creep, again time and temperature-dependent,that can be taken from the output from the microstructural evolution models.

\subsection{Creep Modelling: Estimation of the GB Area Fraction, $A_{f}$, of a Given Phase from Microstructural Evolution Data on Volume Fraction, $V_{f}$}

First it is necessary to establish the relationship between the volume fraction predicted from the microstructural evolution simulation and the volume fraction of phase on a thin layer of grain boundary. If we imagine an array of grains with radius $r$, and that the thickness of the GB precipitate layer is $x$ (Fig.1), then the fraction of the total volume occupied by the GB precipitate layer is given by

$$
\frac{4 \pi r^{2} x}{\frac{4}{3} \pi r^{3}}=\frac{3 x}{r}
$$

Therefore the ratio of the volume fraction of precipitates, $A_{f}$ with thickness $r$, to the overall volume fraction of the precipitates, $V_{f}$, is given by

$$
\frac{A f}{V f}=\frac{r}{3 x}
$$

The value of $V_{f}$ can be estimated from microstructural evolution models for any nickel based alloy for any time and temperature. Thus the volume fraction of any predefined precipitates on the GB from any volume fraction can be obtained for any temperature from the above equation, knowing the thickness of the GB precipitate layer and the grain radius. 


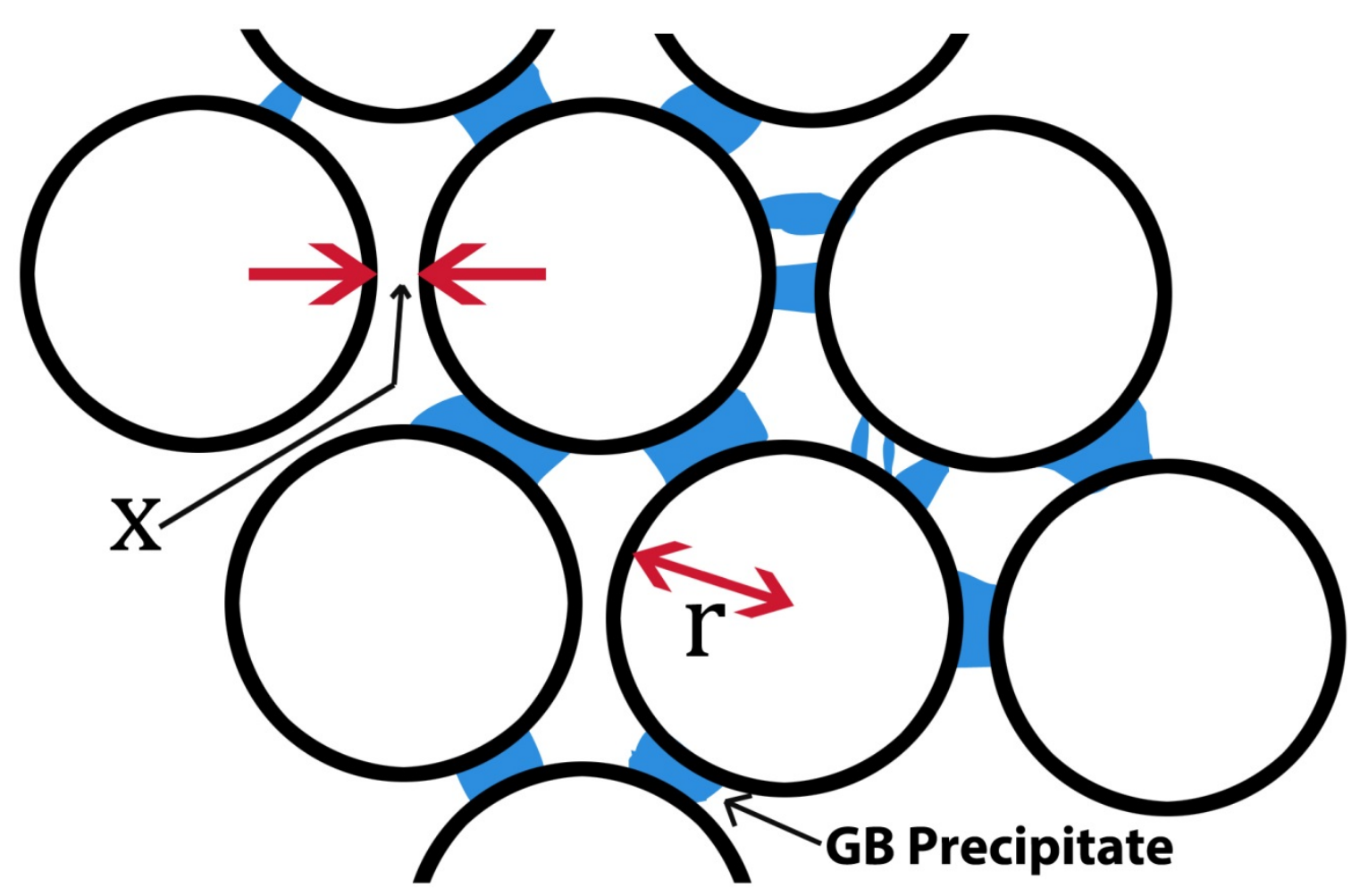

Fig.1 Array of Grains and Grain Boundary Layers used in Prediction of Fracture Properties

\subsection{Creep Modelling: Determination of the Cavitational Damage Parameter, $D_{n}$, on a Grain Boundary with Non-Deformable Precipitates.}

In the same way tertiary creep can be addressed by quantifying the evolution of the grain boundary cavitational damage parameter, $D_{n}$. Raj and Ashby [14-15] have developed equations for the variation of grain boundary cavity density evolution based on grain boundary vacancy transport mechanisms. In the alloy of interest in this paper, IN740, there is another microstructural feature which contributes to grain boundary weakening, namely $G$ phase (complex silicide). This phase has an extremely low fracture toughness $\left(\mathrm{K}_{\mathrm{ic}}\right)$ at room temperature, of the order of $0.1 \mathrm{MPa}$ $\mathrm{m}^{0.5}$. This is important for determination of the room temperature Charpy impact energy for the material. At high temperatures appropriate to creep, the embrittling phase becomes softer and is characterised by a $\mathrm{K}_{\text {ic }}$ of $130 \mathrm{MPa} \mathrm{m}^{0.5}$. If the kinetics of grain boundary vacancy-initiated cavities and grain boundary $\mathrm{G}$ phase evolution are quantifiable, the time dependence of the cavity damage term in the CDM model should be predictable through the following equation. In the case discussed here cavity damage is relatively unimportant, since we are only dealing with the onset of tertiary creep in the predictions that are being made. 
where $\sigma_{\text {boundary }}$ is the stress required to fracture the grain boundary in the lower high temperature $\mathrm{K}_{\text {ic }}$ case $\left(130 \mathrm{MPa} \mathrm{m}^{0.5}\right.$ ), and $\sigma_{\text {applied }}$ is the GB fracture stress in the high $\mathrm{K}_{\text {ic }}$ precipitate-free GB case $\left(140 \mathrm{MPa} \mathrm{m}^{0.5}\right) . \sigma_{\text {boundary }}$ is dependent on the fracture toughness of the grain boundary, as follows

$\sigma_{\text {boundary }}=\mathrm{K}_{\mathrm{IC}} /(\mathrm{TTC})^{0.5}$

where $\mathrm{c}$ is a critical distance, usually the grain size in intergranular fracture analysis. The overall fracture toughness of the GB is given by the weighted fracture toughnesses of the vacancy-initiated cavitated boundary and the boundary occupied by $\mathrm{G}$ phase. This implies that

$K_{I c}=A_{v} \cdot K_{I c}(v)+A_{G} \cdot K_{I c ~(G)}+A_{p p t-f r e e} K_{I c(G B)}$

Where $A_{v}, A_{G}$, and $A_{\text {ppt-free }}$ are the fractional volumes of the GB occupied by cavities, $G$ phase, and precipitate-free GB respectively. The fracture toughness of the vacancy initiated cavities $\mathrm{K}_{\mathrm{Ic}}(\mathrm{v})$, is assumed to be zero, and the fracture toughness of the $\mathrm{G}$ phase is assumed to be, as stated earlier, $130 \mathrm{MPa} \mathrm{m}^{0.5}$, and $\mathrm{K}_{\mathrm{ic}}$ for the precipitate-free GB is assumed to be the ductile fracture toughness of the alloy (140 $\mathrm{MPa} \mathrm{m}^{0.5}$ ). The time dependence of the fractional area terms can be obtained from the Raj-Ashby type analysis for the GB cavities, or the microstructural evolution model simulation for the GB G phase $[10,12]$.

\subsection{Fracture Modelling: Estimation of Charpy Impact Energy from Microstructural Evolution Simulation Data}

The estimation of the Charpy energy can be made from an analysis of the Charpy testing procedure and simple fracture mechanics. The ductile material Charpy energy for Alloy 740 is around $70 \mathrm{~J}$. Although the fracture in this regime is transcrystalline and the test is at room temperature, this is still the only measure we have of fracture resistance of nickel based alloys. Therefore we use the Charpy test results for Alloy 740 after short ageing times at $750^{\circ} \mathrm{C}$ to indicate the fracture toughness of the precipitate-free GB. This fracture toughness is given by

$$
K_{I C}=\sqrt{E \gamma}
$$


Where $E$ is the Young's modulus, and $y$ is the work of fracture per unit area.

Assuming that the area of fracture surface of a Charpy specimen is $6.23 \times 10^{-4} \mathrm{~m}^{2}$ and that the Charpy energy in the ductile regime is $70 \mathrm{~J}$, and that the modulus of stainless steels (assumed to be similar to that of nickel base alloys) is $1.8 \times 10^{11} \mathrm{~Pa}$, $\mathrm{K}_{\mathrm{Ic}}$ for the precipitate-free $\mathrm{GB}$ is

$\mathrm{K}_{\mathrm{Ic}(\text { ppt-frree })}=140 \mathrm{MPa} \mathrm{m}^{1 / 2}$

The room temperature fracture toughness of the material, assuming that vacancyinitiated cavities are unimportant, is given by

$\mathrm{K}_{\mathrm{Ic}(\mathrm{GBRT})}=\mathrm{A}_{\mathrm{G}} \cdot \mathrm{K}_{\mathrm{Ic}(\mathrm{RTG})}+\left(1-\mathrm{A}_{\mathrm{G}}\right) \cdot \mathrm{K}_{\mathrm{Ic}(\mathrm{ppt} \text {-free })}$

Where $A_{G}$ is the volume fraction of $G B G$ phase precipitate, taken from the total volume fraction of $G$ phase taken from the microstructural evolution model, as shown in the previous section; $\mathrm{K}_{\text {ic }(\mathrm{RTG})}$ is the room temperature fracture toughness of the $\mathrm{G}$ phase, $0.1 \mathrm{MPa} \mathrm{m}^{0.5}$; and $\mathrm{K}_{\text {ic (ppt-free) }}$ is the fracture toughness of the precipitate-free $\mathrm{GB}$, assumed to be the room temperature fracture toughness of the material, 140 MPa $\mathrm{m}^{0.5}$.

The influence of the increasing amount of GB G phase forming as time proceeds at high temperature can then be converted into a Charpy value by taking the values of $\mathrm{K}_{\mathrm{Ic}(\mathrm{GBRT})}$ calculated for varying times at high temperature using the microstructural evolution data and converting it to a Charpy value as follows.

$$
\text { Charpy Value }=K_{I C(G B R T)}^{2} \frac{\text { Area of deformation zone in test }}{E}
$$

Where $E$ is Young's modulus and the area of the deformation zone is taken as $6.23 \mathrm{x}$ $10^{-4} \mathrm{~m}^{2}$. This conclusion is arrived at from the following analysis.

$$
K_{I c}=\sigma_{y} \sqrt{\pi c}
$$

The size of the deformation zone is a square of side length $c$, and $\sigma_{y}$ is the yield strength of the alloy, assumed to be $500 \mathrm{MPa}$ and $\mathrm{K}_{\mathrm{Ic}}$ is equal to $\mathrm{K}_{\mathrm{Ic}(\mathrm{ppt} \text {-free). }}$.

\subsection{Application of Models to Alloys 740 and 740H: Alloy Data and Microstructural Evolution Predictions}

Alloys 740 and $740 \mathrm{H}$ have compositions listed in Table 1. 


\begin{tabular}{|c|c|c|c|c|c|c|c|c|c|c|c|c|c|}
\hline \multirow[b]{2}{*}{ Alloy } & \multicolumn{12}{|c|}{ Chemical composition weight \% } & \multirow[b]{2}{*}{$\mathrm{Ni}$} \\
\hline & C & $M$ & Si & $A I$ & $\mathrm{Cr}$ & $\mathrm{Cu}$ & Co & Mo & $F e$ & $T i$ & $N b$ & $B$ & \\
\hline IN740 & 0.034 & 0.3 & 0.58 & 1.04 & 24.5 & -- & 19.8 & 0.6 & 0.45 & 1.64 & 2.4 & -- & $\mathrm{Bal}$ \\
\hline IN740H & 0.03 & - & 0.15 & 1.35 & 25 & - & 20 & 0.5 & - & 1.35 & 1.5 & 0.001 & Bal. \\
\hline
\end{tabular}

Table 1: Compositions of IN740 and IN740H alloy investigated

The Al diffusion coefficient temperature dependence for both alloys is described by the following using the Arrhenius approach:

$$
D=D_{0} e^{\frac{-E_{A}}{R T}}
$$

The frequency factor, $D_{0}$, is:

$2.4 \times 10^{-4} \mathrm{~s}^{-1}$ for alloy IN740 and $4.46 \times 10^{-4} \mathrm{~s}^{-1}$ for alloy IN740H;

The activation energy, $E_{A}$, is:

$271.8 \mathrm{kJmol}^{-1}$ for alloy IN740 and $277.06 \mathrm{kJmol}^{-1}$ for alloy IN740H.

The thermodynamic data (heats of solution) used to produce the forecasted curves are taken from databanks from MATCALC.

The alloys being studied were assumed to have a solution treatment and quench, followed by a 4 hour ageing heat treatment at $750^{\circ} \mathrm{C}$, or 24 hours at $700^{\circ} \mathrm{C}$, to bring out the intra-granular gamma prime phase. Grain boundary phases present are $G$ phase, eta, and $\mathrm{M}_{23} \mathrm{C}_{6}$. The evolution of the phases using the MATCALC model at $750^{\circ} \mathrm{C}$ and $700^{\circ} \mathrm{C}$ for Alloys 740 and $740 \mathrm{H}$ are shown in Figs. 2-5. 


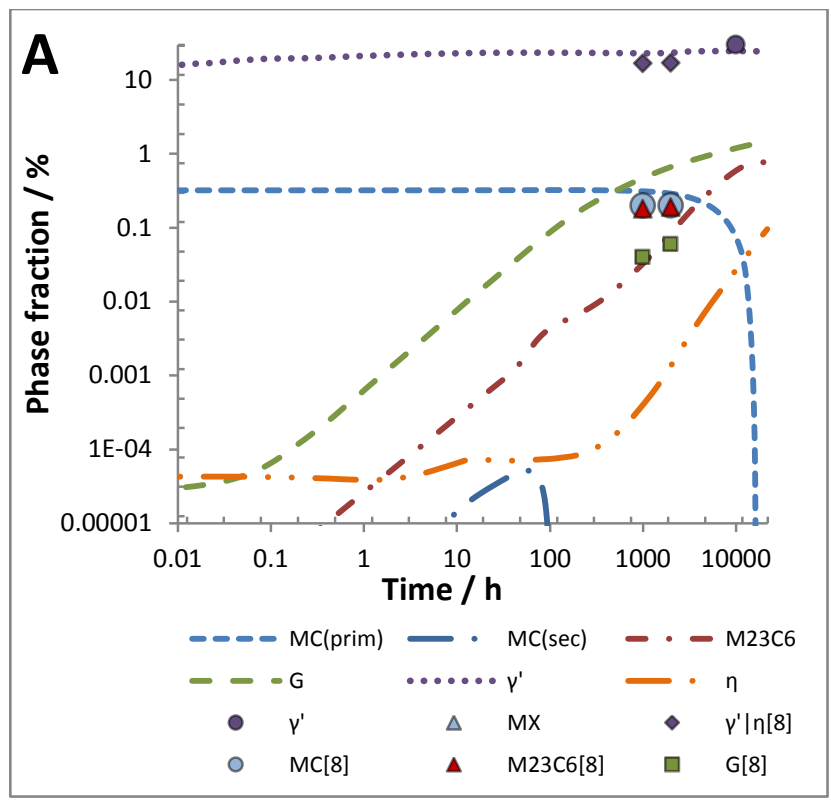

Fig. 2 Evolution of Phases in Alloy 740 at $700^{\circ} \mathrm{C}$

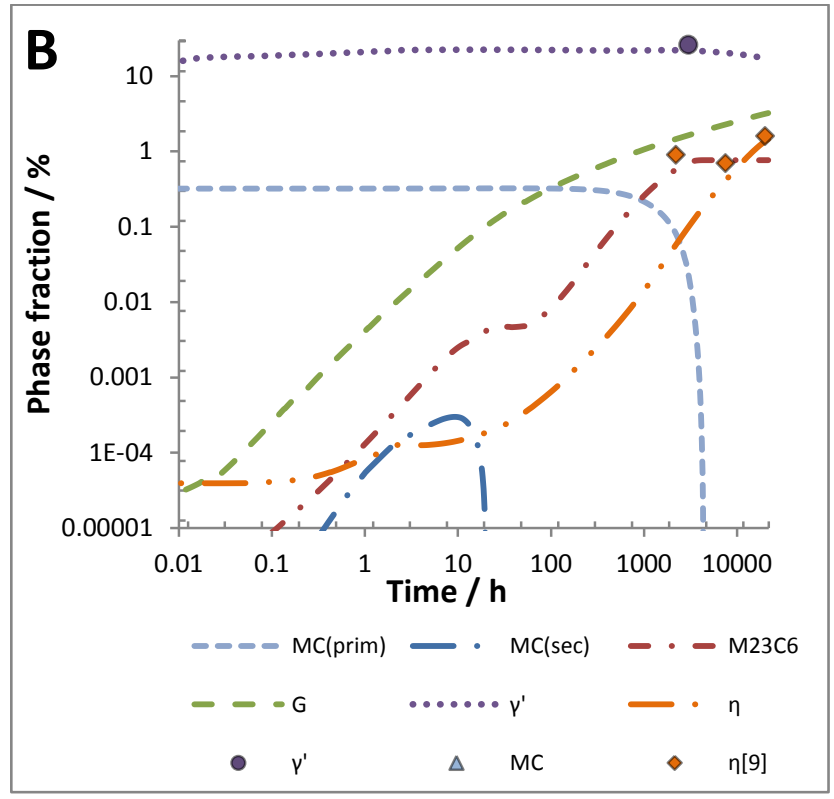

Fig. 3 Evolution of Phases in Alloy 740 at $750^{\circ} \mathrm{C}$ 


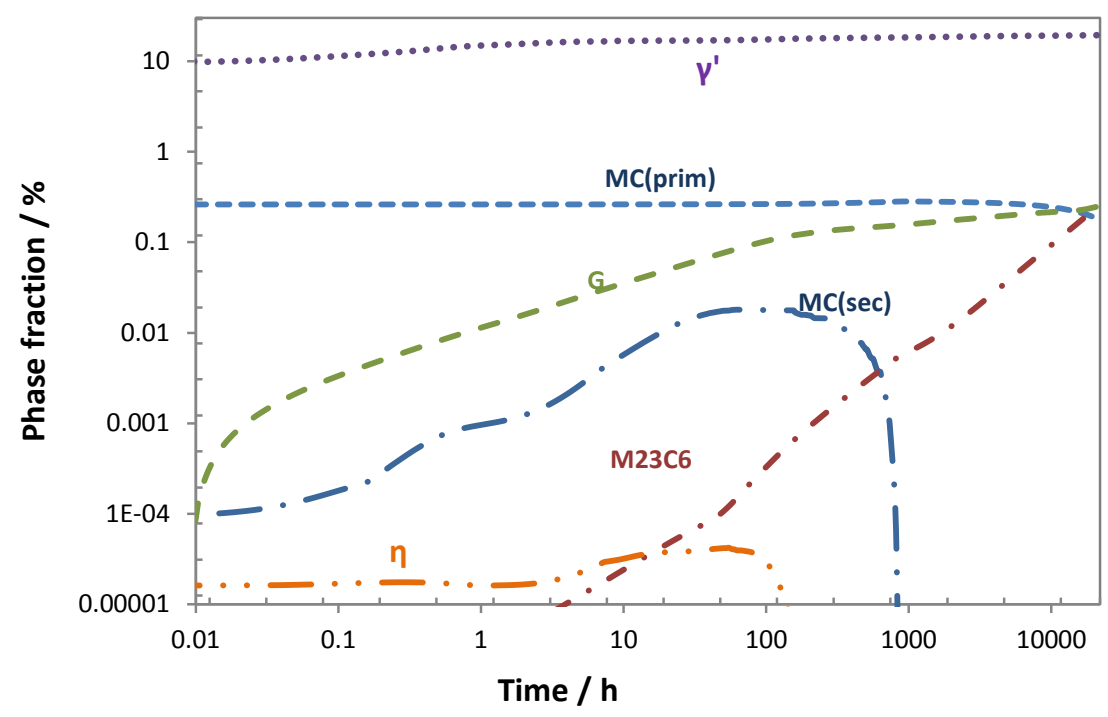

Fig. 4 Evolution of Phases in Alloy $740 \mathrm{H}$ at $700^{\circ} \mathrm{C}$

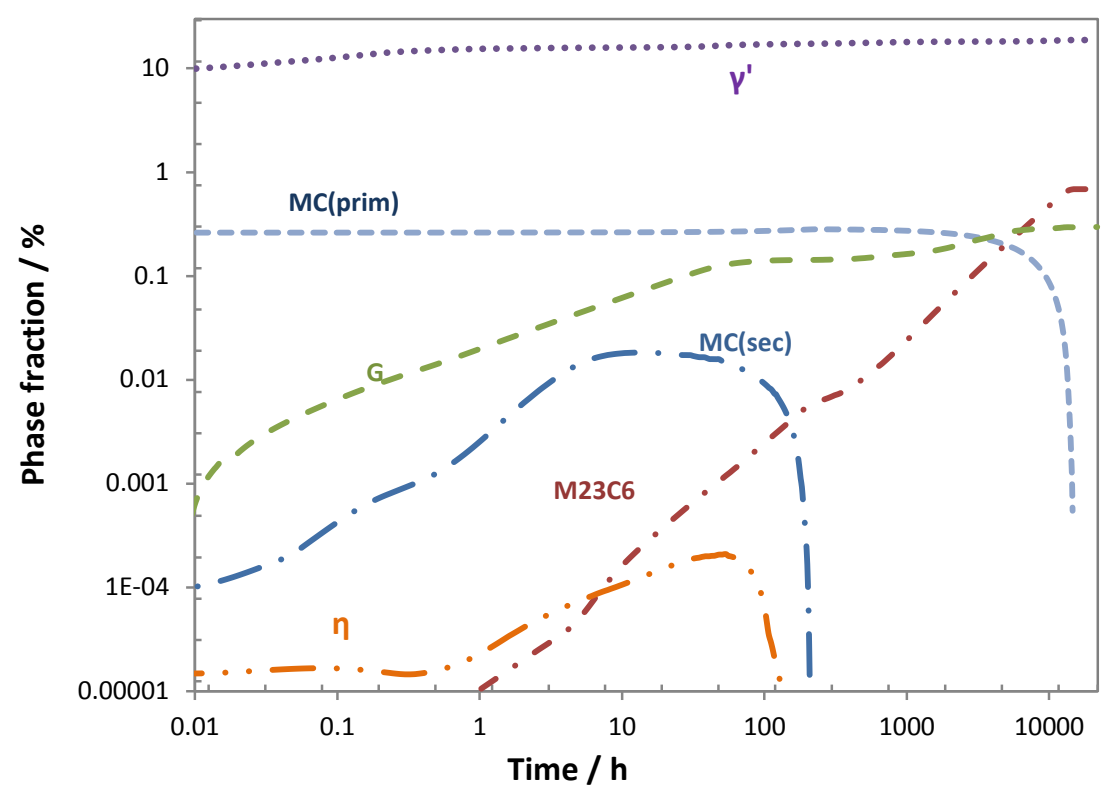

Fig. 5 Evolution of Phases in Alloy $740 \mathrm{H}$ at $750^{\circ} \mathrm{C}$

It can be seen that the largest volume fraction GB phase is G phase. This phase is therefore used to describe the volume fraction changes that are used as input to the GB coverage, that is the percentage of phase in the GB layer of thickness, $x$, where $x$ is assumed to be $50 \mathrm{~nm}$. These data are fed to the models for the fracture toughness of the material. The fracture toughness values are converted to Charpy values, assuming the size of the plastic zone ahead of the crack is $6.23 \times 10^{-4} \mathrm{~m}^{2}$. 


\subsection{Application of Models to Alloys 740 and 740H: Fracture Predictions}

The data on GB volume fraction of $G$ phase precipitates taken from section 6.0 is used to predict Charpy impact energy as a function of time at $750^{\circ} \mathrm{C}$ using the approach described in Section 5.1. The results are shown in Fig.6.

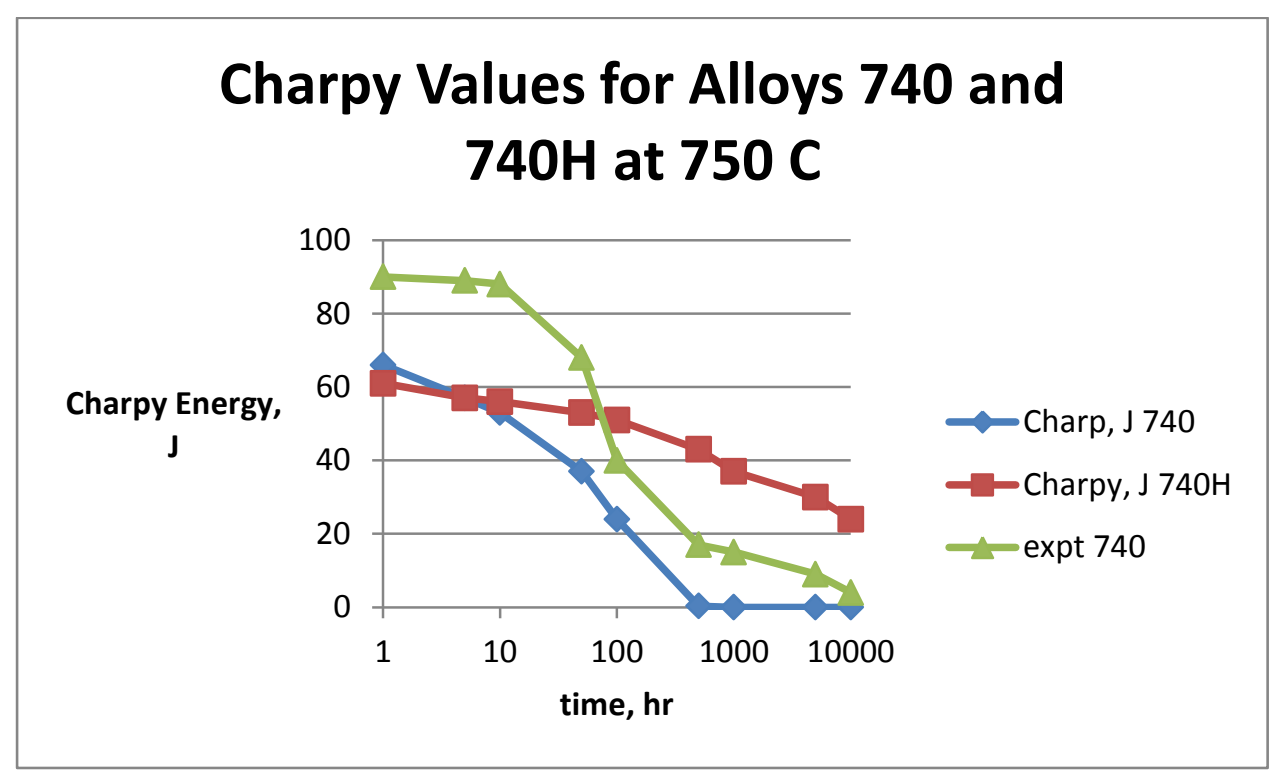

Fig. 6 Room Temperature Charpy Energies as a Function of Time at $750^{\circ} \mathrm{C}$ for Alloys 740 and $740 \mathrm{H}$. Experimental Results for Alloy 740 Are Also Included

The experimental data are taken from EON [16] for a range of austenitic steels and nickel based alloys and these are shown in Fig. 7 . 


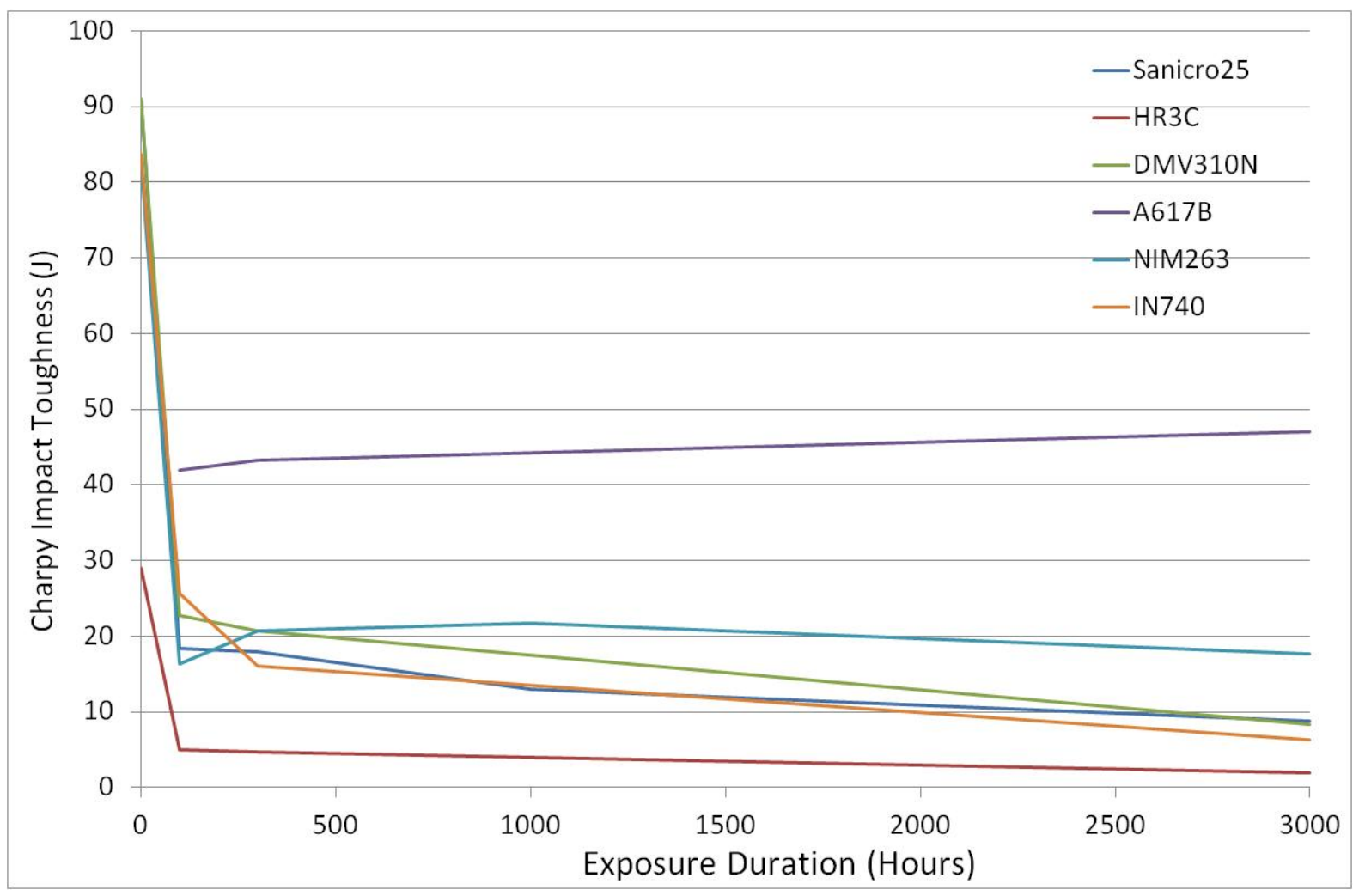

Fig.7 Experimental Room Temperature Charpy Energies for a Range of Nickel Based Alloys and Stainless Steels as a Function of Time at $750^{\circ} \mathrm{C}$

The results in Fig. 6 indicate that the drop in Charpy Energy occurs much earlier in Alloy 740 than in Alloy $740 \mathrm{H}$, and this trend is supported by experiment. Alloy $740 \mathrm{H}$ retains a higher fracture toughness at room temperature than Alloy 740 ; indeed this is the reason why Alloy $740 \mathrm{H}$ was developed. The modelling has shown that the drop in Charpy Energy coincides with volume fractions of grain boundary $G$ phase rising above volume fractions of $0.1 \%$ (see Figs. 3 and 5).

\subsection{Application of Models to Alloys 740 and $\mathbf{7 4 0 H}$ : Creep Curve Prediction using Modelled Dp}

$\mathrm{Dp}$ is calculated from

$$
D_{p}=1-\frac{P_{i}}{P_{t}}
$$

Where $P_{\mathrm{i}}$ is the initial gamma prime interparticle spacing, taken as $20 \mathrm{~nm}$ after ageing at either $700^{\circ} \mathrm{C}$ or $750^{\circ} \mathrm{C}$, and $\mathrm{P}_{\mathrm{t}}$ is the interparticle spacing after time $\mathrm{t}$. These data are taken from the microstructural evolution modelling predictions, shown in Figs. 8 and 9. 


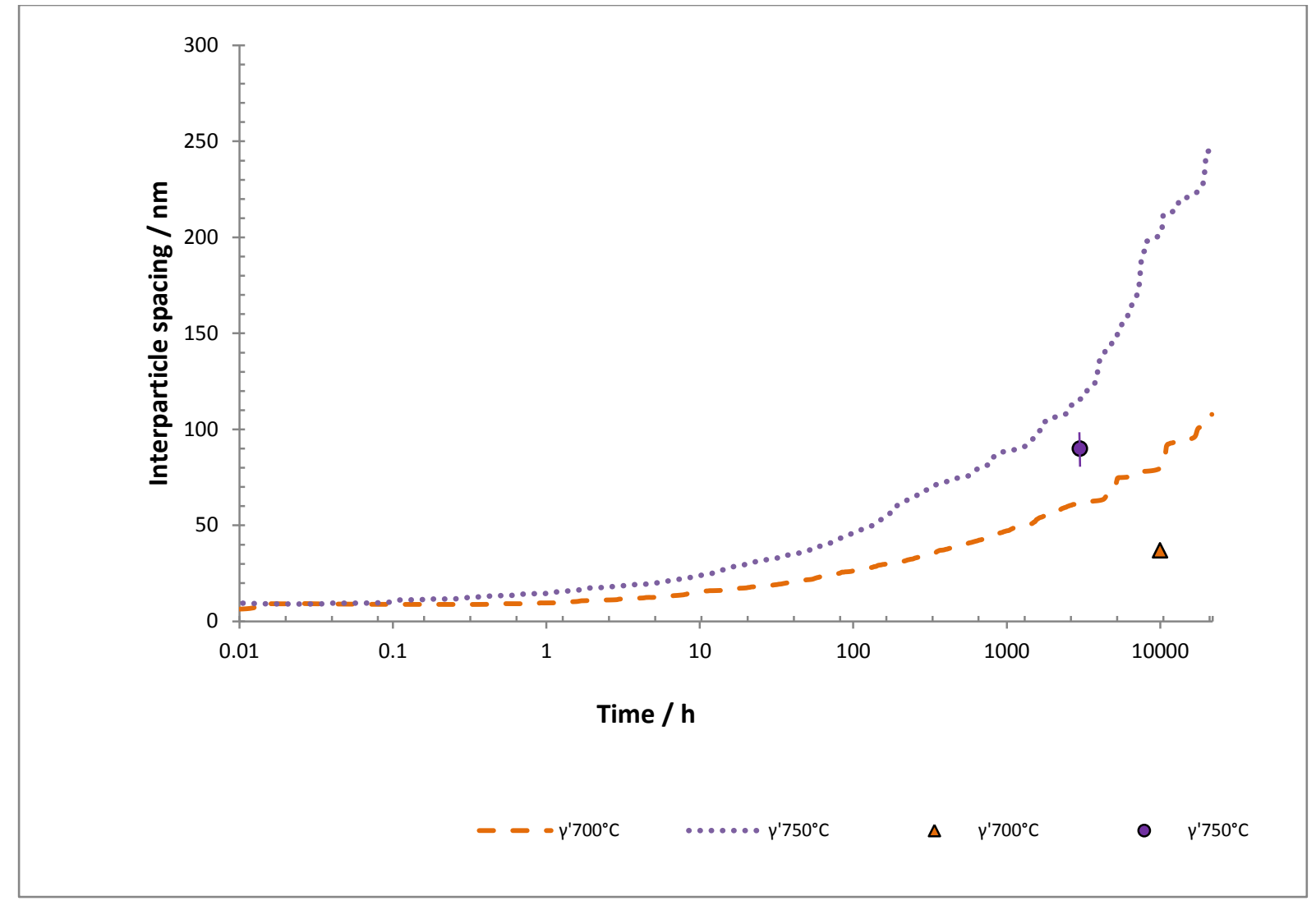

Fig. 8 Microstructural Evolution Model Predictions of Gamma Prime Interparticle Spacings in Alloy 740 at $700^{\circ} \mathrm{C}$ and $750^{\circ} \mathrm{C}$, together with Two Experimental Points 


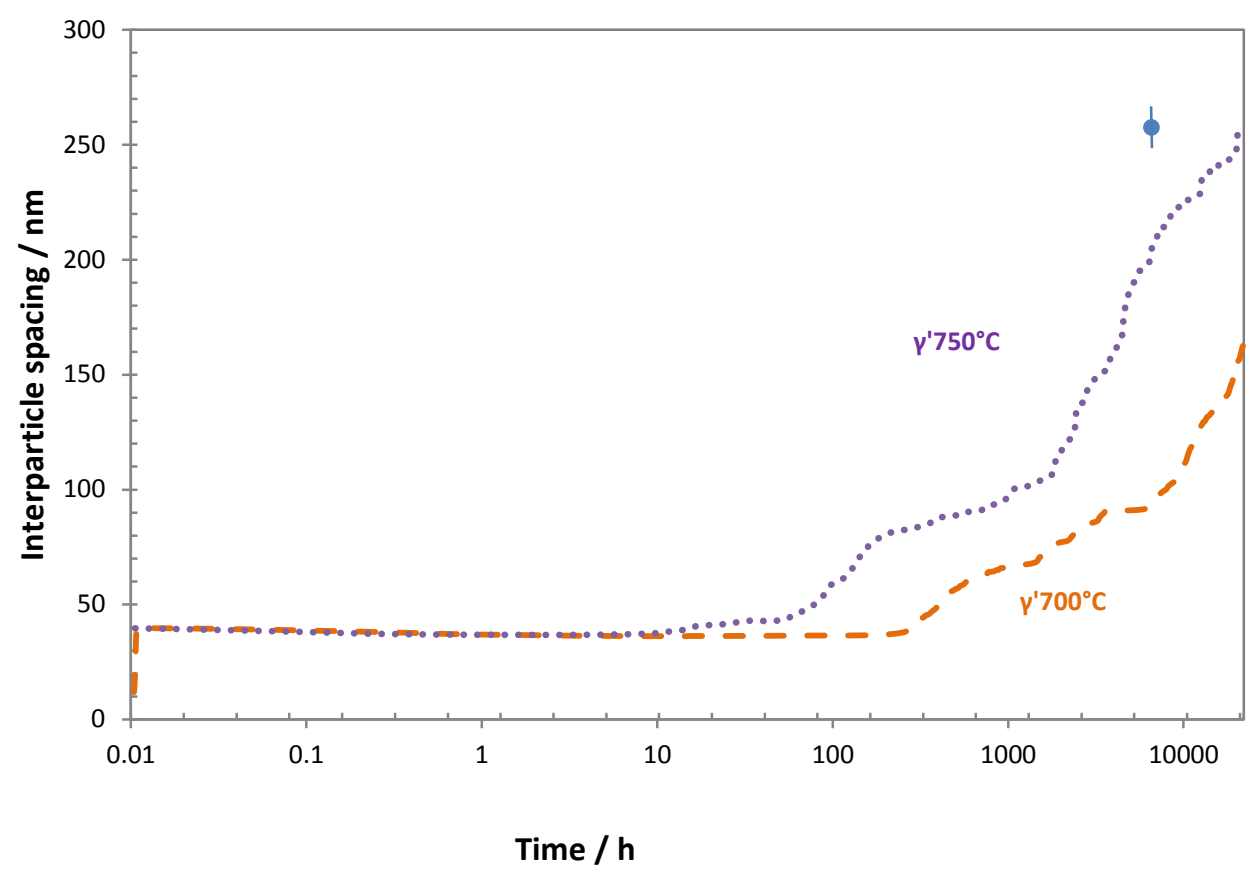

Fig.

9 Microstructural Evolution Model Predictions of Gamma Prime Interparticle Spacings in Alloy $740 \mathrm{H}$ at $700^{\circ} \mathrm{C}$ and $750^{\circ} \mathrm{C}$

Thus the appropriate $\mathrm{Dp}$ value can be assigned to the CDM model equation in section 3 for a range of times at different temperatures for both Alloy 740 and Alloy $740 \mathrm{H}$, and a creep curves can be produced as a result. Examples are shown for a stress of $273 \mathrm{MPa}$ at $700^{\circ} \mathrm{C}$ and $172 \mathrm{MPa}$ at $750^{\circ} \mathrm{C}$ in Figs. 10 and 11 . Good fits are observed.

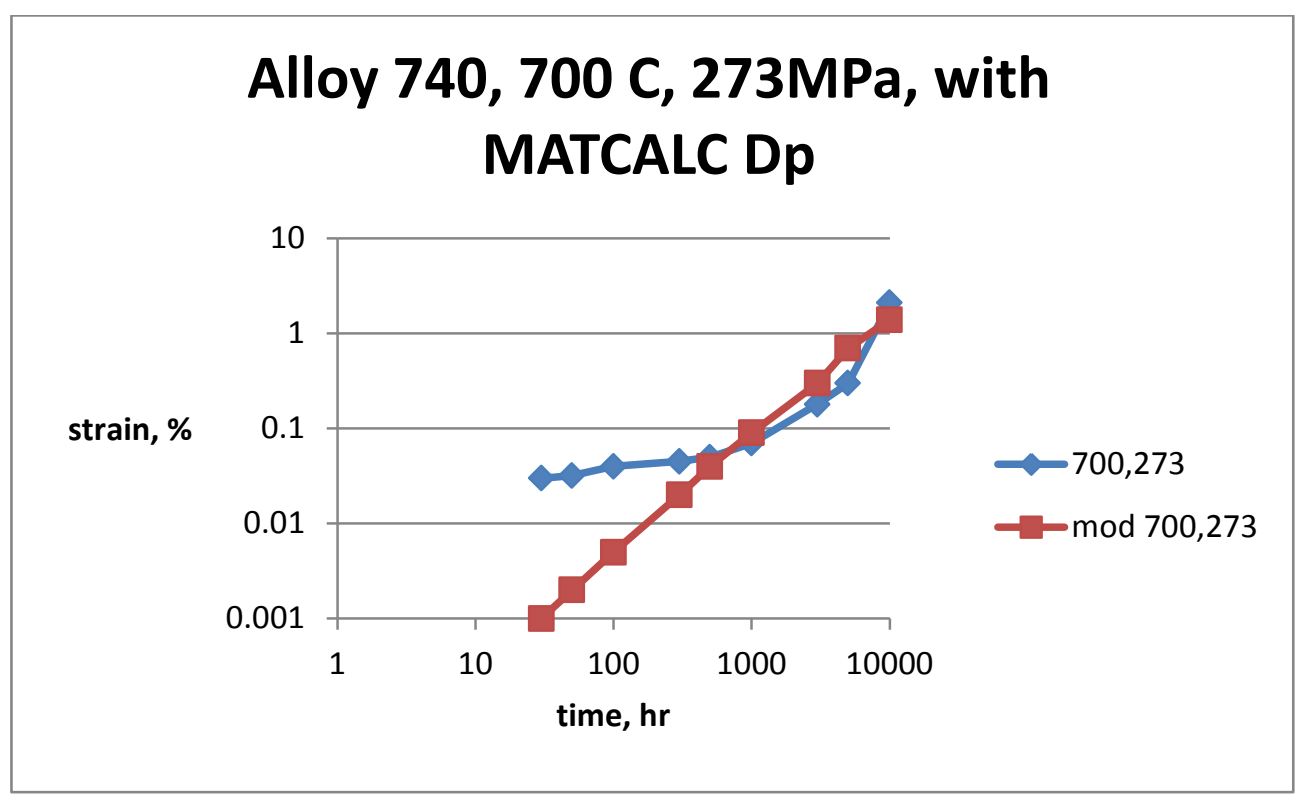


Fig. 10 Predicted (mod 700,273) and Experimental Creep Curves for Alloy 740 at $700^{\circ} \mathrm{C}$ and $273 \mathrm{MPa}$ Stress, using only the Interparticle Spacing Dp Predictions

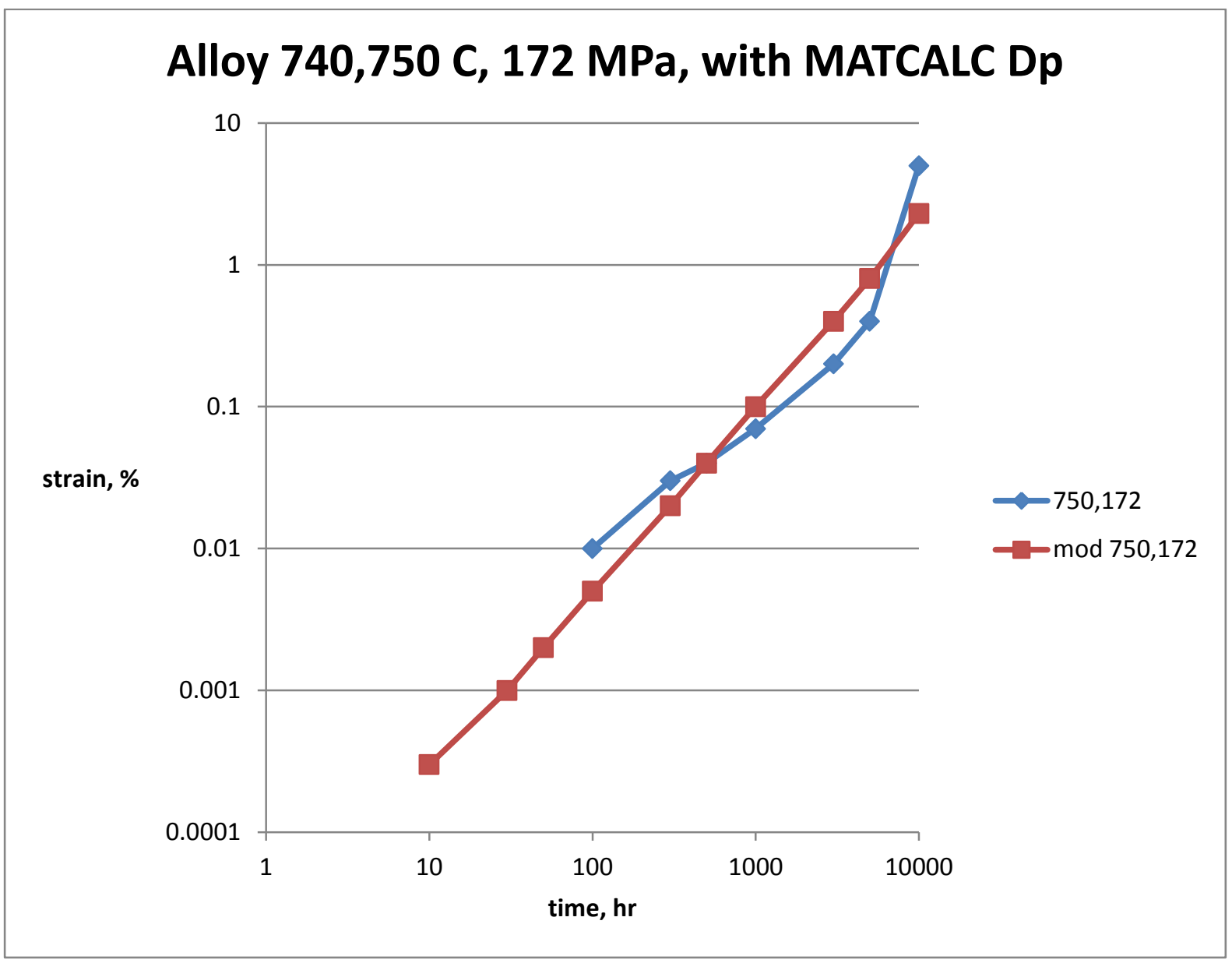

Fig. 11 Predicted (mod 750,172) and Experimental Creep Curves for Alloy 740 at $750^{\circ} \mathrm{C}$ and $172 \mathrm{MPa}$ Stress, using only the Interparticle Spacing Dp Predictions The effects of inclusion of the modified Dn parameter, as well as the Dp parameter in the CDM modelling is shown for Alloys 740 and $740 \mathrm{H}$ at $700^{\circ} \mathrm{C}$ and $750^{\circ} \mathrm{C}$ in Figs.12-15. 


\section{Alloy 740, $750 \mathrm{C}, 172 \mathrm{MPa}$, with MATCALC Dp and FT Dn}

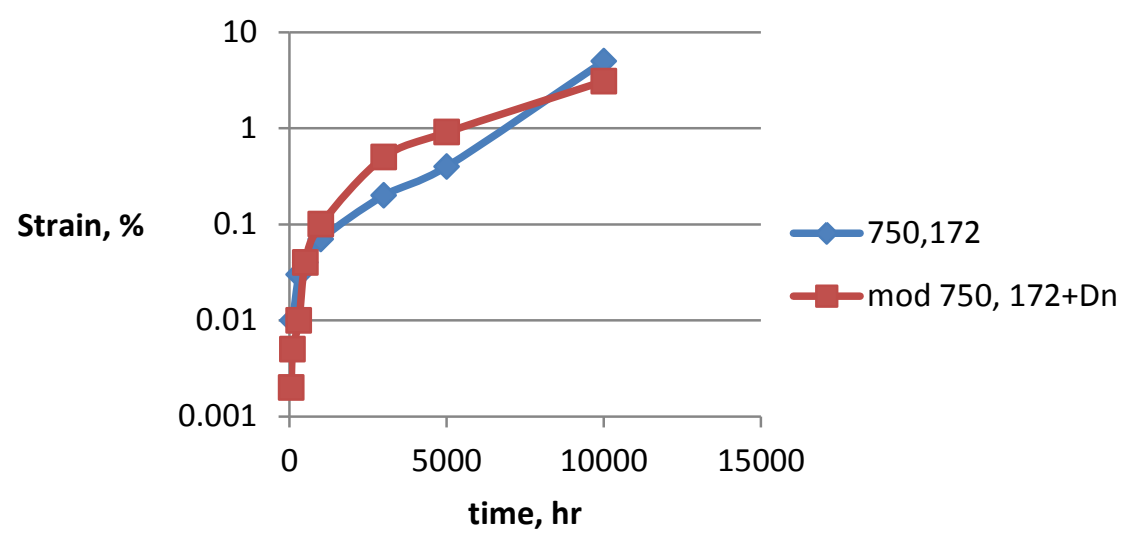

Fig. 12 Experimental and Predicted Creep Curves for Alloy 740 at $750^{\circ} \mathrm{C}$, using Microstructurally-Based Input for the Dn and Dp Parameters

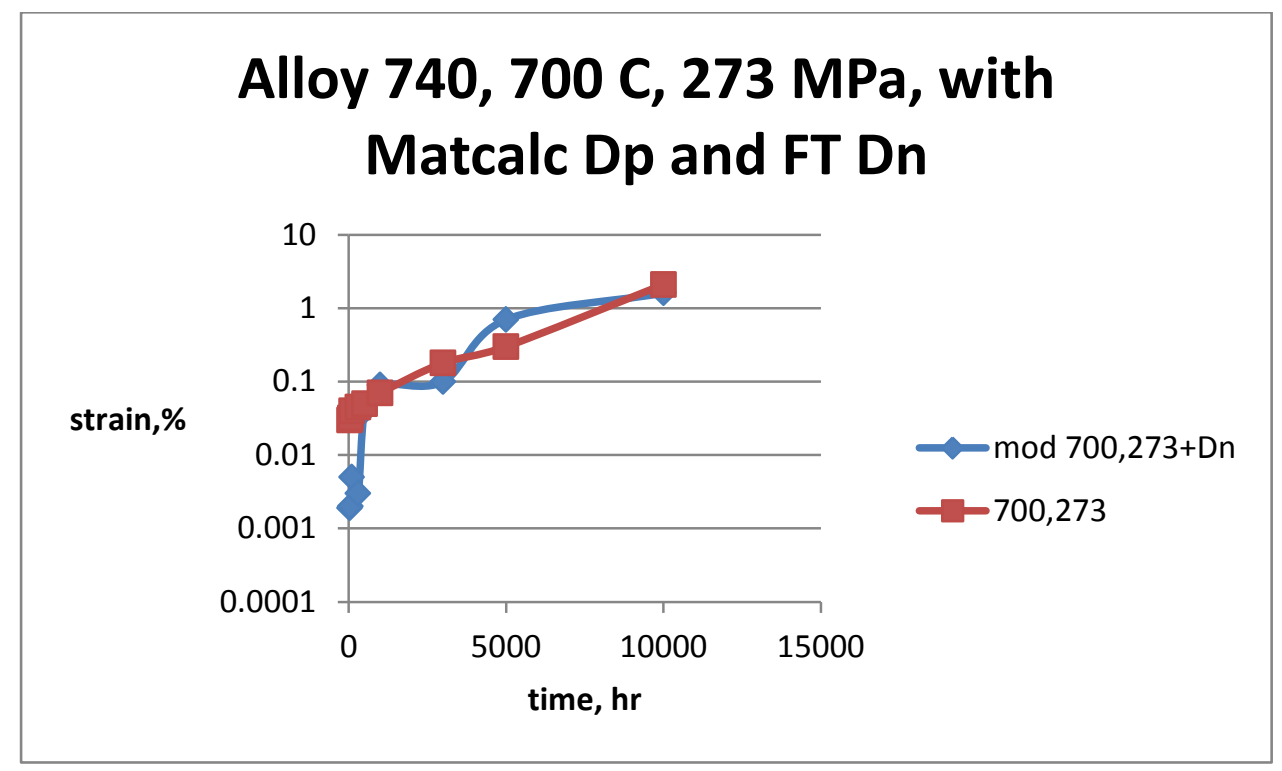

Fig.13 Experimental and Predicted Creep Curves for Alloy 740 at $700^{\circ} \mathrm{C}$, using Microstructurally-Based Input for the Dn and Dp Parameters 


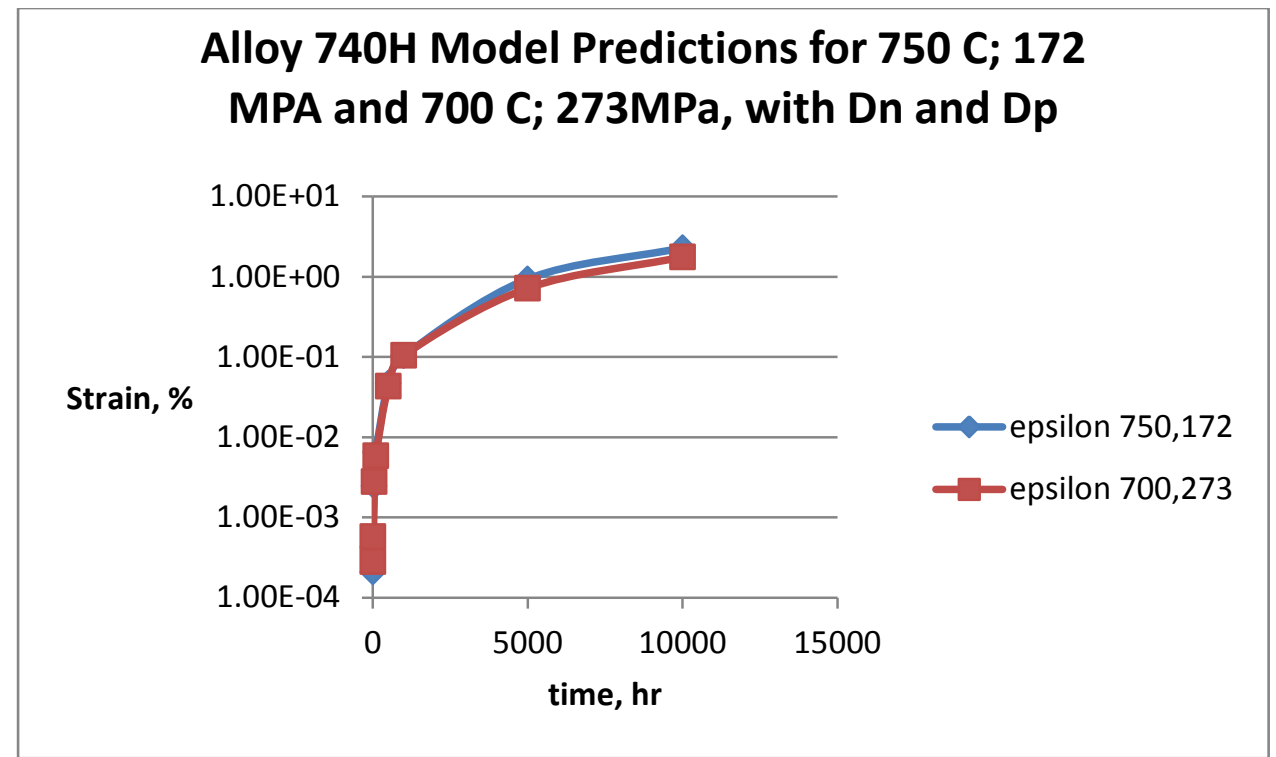

Fig.14 Predicted Creep Curves for Alloy $740 \mathrm{H}$ at $700^{\circ} \mathrm{C}$ and $750^{\circ} \mathrm{C}$, using Microstructurally-Based Input for the Dn and Dp Parameters

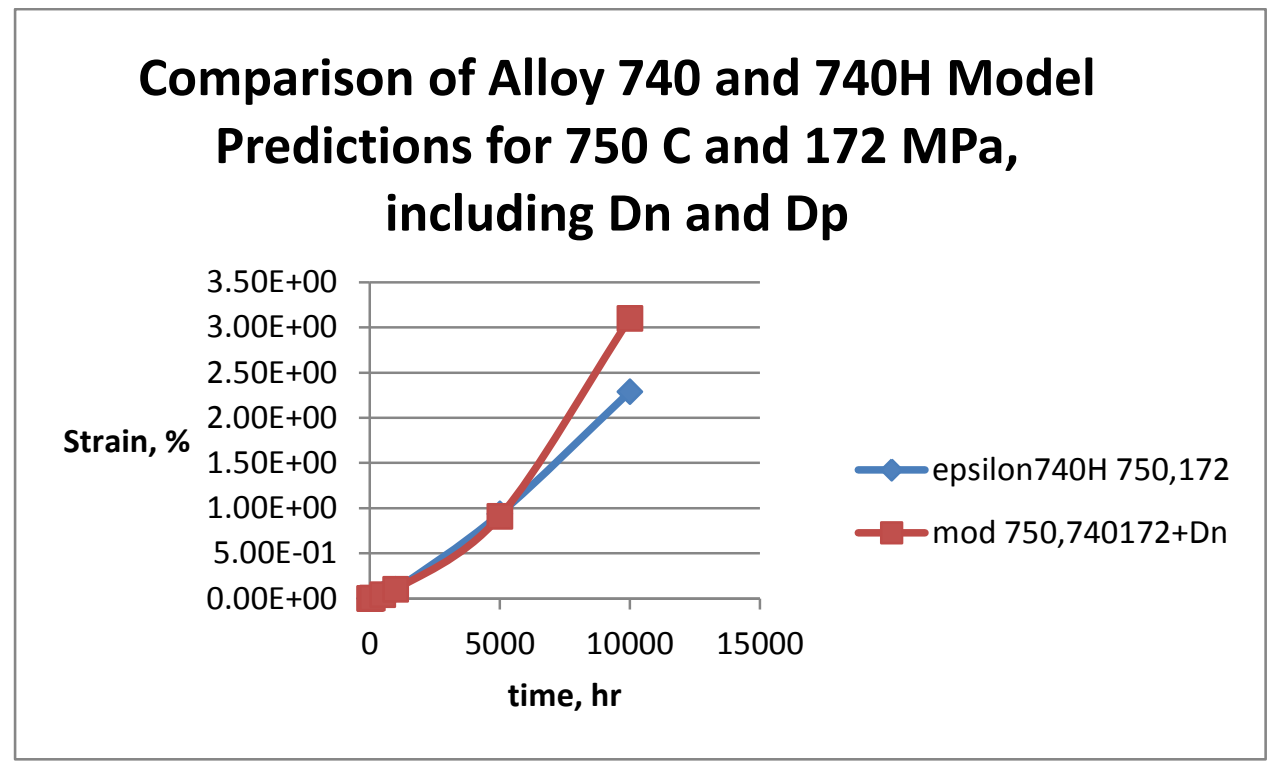

Fig.15 Comparison of Predicted Creep Curves for Alloys 740 and $740 \mathrm{H}$ at $750^{\circ} \mathrm{C}$, using Microstructurally-Based Input for the Dn and Dp Parameters

These graphs show that the $D_{n}$ parameter affects the tertiary creep prediction, giving a better fit after long times with the experimental creep curve in Alloy 740 at $700^{\circ} \mathrm{C}$ (compare Figs. 10 and 13).

Furthermore Fig. 15 shows superior predicted creep properties in the tertiary regime for Alloy $740 \mathrm{H}$, and this is because of the GB embrittling effect of the increased GB coverage of $\mathrm{G}$ phase after long times in Alloy 740, as compared with Alloy $740 \mathrm{H}$. 


\section{Discussion}

The choice of the effective area of the Charpy specimen deserves some comment. For ductile materials the plastic zone is likely to be larger than the cross sectional area of the Charpy specimen $\left(10^{-4} \mathrm{~m}^{2}\right)$. Therefore the analysis at the end of section 5.1 seems justified to give an area $\left(\mathrm{c}^{2}\right)$ of $6.23 \times 10^{-4} \mathrm{~m}^{2}$. This analysis allows us to start with acceptable values of the fracture toughness of tough stainless steels and nickel based alloys (140 MPa $\mathrm{m}^{0.5}$ ) to calculate the work of fracture and hence the Charpy energy at a value close to that observed experimentally (70J).

The use of the microstructural evolution models highlight the fact that the gamma prime coarsening occurs at similar rates in Alloy 740 and Alloy $740 \mathrm{H}$ (Fig. 15), leading to similar predicted creep strains in the secondary regime. On the other hand, in the tertiary regime, the earlier presence of GB G phase in Alloy 740 leads to higher predicted creep strains than in Alloy $740 \mathrm{H}$.

The use of the microstructual evolution models similarly shows deeper insight into the difference in factors controlling the fracture properties of Alloys 740 and $740 \mathrm{H}$. The delay in the onset of predicted Charpy energy reduction at $750^{\circ} \mathrm{C}$ (Fig. 6) is clearly explained by the earlier onset of $\mathrm{G}$ phase coverage on the GBs in Alloy 740 than in Alloy $740 \mathrm{H}$.

It is interesting to note in Section 4.2, that in order for the microstructural evolution predictions to predict fracture and creep properties accurately, the fracture behaviour of precipitates on GBs has to change from a situation where the $\mathrm{K}_{\mathrm{ic}}$ is $0.1 \mathrm{MPa} \mathrm{m}^{0.5}$ to $a \mathrm{~K}_{\mathrm{ic}}$ value of $130 \mathrm{MPa} \mathrm{m}^{0.5}$ to account for the alloy system changing from room temperature to a temperature where creep is likely.

Finally the key prediction, which is supported by limited experimental observation, is that Alloy $740 \mathrm{H}$ has superior fracture and creep properties to Alloy 740 because of the earlier onset of GB G phase production in Alloy 740. This is because of the lower $\mathrm{Ti}$ and $\mathrm{Nb}$ content in Alloy $740 \mathrm{H}$. The lower Ti content is clearly wellcompensated with additional $\mathrm{Al}$, because clearly the gamma prime coarsening rates must be reasonably similar for the creep rates in the two alloys to be so similar (Fig. 15). The other interesting aspect to this is the absence of the influence of the eta phase. Previously this was thought to the be damaging phase but glancing at Figs. 4-5 indicates that eta is present in very small proportions, and disappears altogether after 100 hours at $750^{\circ} \mathrm{C}$.

The models further indicate that secondary creep is controlled in these nickel based alloys by the inter-particle spacing of the gamma prime phase. This is in contrast with microstructural damage based creep models using the back-stress approach on 20/25 Cr/Ni steels by Sandstrom [8-9], where the GB carbides are shown to be the secondary creep controlling phase.

\section{Conclusions}


Microstructural evolution models have been applied to two nickel based alloys, Alloy 740 and Alloy $740 \mathrm{H}$. These models have indicated differences in the evolution sequences of the intra-granular gamma prime phase and grain boundary $\mathrm{G}$ phase.

These differences explain why Alloy $740 \mathrm{H}$ exhibits better room temperature Charpy impact energy properties than Alloy 740 because increasing quantities of $G$ phase accumulate on the GBs in a given time in Alloy 740 . Furthermore the presence of substantial amounts of GB G phase after relatively short times at high temperature cause an increase in the creep strain in the tertiary creep regime in Alloy 740 . The onset of GB G phase in Alloy $740 \mathrm{H}$ is inhibited because of the lower levels of $\mathrm{Ti}$ and $\mathrm{Nb}$, and tertiary creep only sets in after longer times in this alloy.

Gamma prime coarsening rates in both alloys are predicted to be similar, with the result that the creep rates in the secondary regime are almost identical.

The modelling/experimental approach described is useful in highlighting changes in fracture toughness of phases present in the alloys in different temperature regimes.

\section{References}

[1] R. Viswanathan, W. Bakker: "Materials for Ultrasupercritical Coal Power Plants-Boiler Materials”, Part 1. Journal of Materials Engineering and Performance, Vol. 10 (2001), pp. 81-95

[2] T. B. Gibbons: "Superalloys in modern power generation applications”, Materials Science and Technology, Vol. 25 (2009), pp. 129-135

[3] A. Sharma, B.J J. P. Buhre, S. Richardson, C. Spero, T. Wall: "Fired Supercritical Boilers Operational Issues and Coal Quality Impacts”, Technical Note 20. CCSD(Cooperative Research Centre for Coal in Sustainable Development) Report, 2002.

[4] R. Viswanathan et al: "U.S. Program on Materials Technology for Ultra-Supercritical Coal Power Plants”, Journal of Materials Engineering and Performance Vol. 14 (2005), pp. 281-292

[5] R. C. Reed: “The Superalloy Fundamentals and Applications” (Cambridge University Press, 2006)

[6] J. P. Shingledecker, R. W. Swindeman, Q. Wu, V.K. Vasudevan: "Creep Strength of High Temperature Alloys For Ultra-supercritical Steam Boilers”, 4th EPRI Conference on Advances in Materials Technology for Fossil Power Plants, 2007

[7] M. J. Donachie, S. J. Donachie: SUPERALLOYS A Technical Guide. (ASM International: 2002)

[8] R. Sandström, M. Farooq, J. Zurek: "Basic Creep models for 25Cr20NiNbN austenitic stainless steels”, Materials Research and Innovation, Vol. 17 (2013), pp. 355-359

[9] S. Vujic, C. Beal, C. Sommitsch, M. Farooq, R. Sandström, J. Zurek: “ Modelling and optimizing precipitation in creep resistant austenitic steel 25Cr-20Ni-Nb-N”, 7th Int. Conf. on Advances in Materials and Technology for Fossil Power Plants, 2013, pp. 11631172 
[10] Y. F. Yin, R. G. Faulkner, “Continuum damage mechanics modelling based on simulation of microstructural evolution kinetics”, Materials Science and Technology, Vol. 22, n. 8 (2006), pp.929-936 B.

[11] Dyson: "Use of CDM in marerials modelling and component creep life prediction", Journal of Pressure Vessel Technology, Vol. 122 (2000), pp. 281-296

[12] S. F. Di Martino, R. G. Faulkner and S. C. Hogg, "Characterisation of microstructure and creep predictions of alloy IN740 for ultrasupercritical power plants”, Materials Science and Technology 2014; 31(1), 48-58.

[13] L. Ratke, P.W. Woorhees, "Growth and Coarsening, Ostwald ripening in materials processing”, (2002, Springer)

[14] Raj, R., "Separation of Cavitation-Strain and Creep-Strain During Deformation”, Journal of the American Ceramic Society, Vol. 65, (1982) p. C-46

[15] A.C.F. Cocks, M.F. Ashby, “On creep fracture by void growth”, Progress in Materials Science, Vol. 27, (1982), pp. 189-244

[16] EON, Private communication

\section{Acknowledgements}

The investigation is part of the collaborative project ENER/FP7EN/249809/MACPLUS, funded by the EU within the FP7 framework. 